\title{
Understanding long-term human-climate-ecosystem interactions for sustainability
}

\author{
Jacob Freeman ${ }^{1,2}$, E. Robinson ${ }^{1}$, C. Latorre ${ }^{3}$ and M. Cannon ${ }^{1}$
}

\section{The prehistory of human-environment} interactions is a source of knowledge critical for meeting the challenges of a globalizing planet confronting population growth and climate change. The PEOPLE 3000 working group (pastglobalchanges.org/people3000) combines archaeological and paleoecological case studies with mathematical modeling to investigate how co-evolving human societies and ecosystems can successfully cope with the interrelated forces of globalization, population growth, and climate change, and why, in some cases, societies fail to cope with these interrelated forces and reorganize accordingly.

\section{PEOPLE 3000 has two interrelated} objectives. First, we seek to describe and explain basic patterns of human population ecology by building large radiocarbon datasets and integrating these datasets with paleoenvironmental datasets and formal, mathematical models. Second, we seek to evaluate concepts from contemporary policy documents from the long-term perspective offered by the integrated analysis of formal models, radiocarbon, and paleoenvironmental datasets.

For example, Freeman and colleagues synthesized and used large datasets of archaeological radiocarbon to document that the energy output of human societies over the last 10,000 years displays synchrony - the simultaneous fluctuation of human populations (Freeman et al. 2018). Synchrony is a well-documented process in the population ecology of non-human animals, but this was the first time it was described among human populations. This work describes a basic population ecology process - synchrony - that may be used to inform sustainability research. Preliminary evidence suggests that human synchrony results from globalization rather than simultaneous responses to climate. Similarly,
Robinson et al. (2019) integrate radiocarbon records with downscaled, transient paleoclimate models to examine how the distribution of population in the Western USA and climatic zones coevolved over time. They find strong evidence of climate-zone filling and the "packing" of people into climate zones over time, which may have contributed to late Holocene population collapses.

Finally, in one of our ongoing projects, PEOPLE 3000 is evaluating the policy concept of "climate-smart agriculture". Climate-smart agriculture mitigates ecological degradation enhances productivity, and maintains the robustness of production to climate change (Lipper et al. 2014). Yet, the relationships between these "triple win" processes are not well understood over the long term. In fact, these tenets conflict with a large body of theory. Models from resilience theory suggest that increasing productivity necessarily means giving up robustness (Carpenter et al. 2015). Large datasets of archaeological radiocarbon allow us to study the fundamental process of population stability to evaluate whether prehistoric societies undergoing population growth and climate change achieved simultaneous increases in the productivity and the robustness of agriculture or traded these off. Our results suggest partial support for the core tenet of climate-smart agriculture that societies can simultaneously increase productivity and robustness (Fig. 1).

Over the next year, PEOPLE 3000 seeks to expand our coverage to develop biogeographic analyses of human energy dynamics and continue to evaluate policy concepts using the longterm perspective provided by paleorecords. Specifically, we will:

- Develop records of paleoclimate and, more importantly, ecosystem change to integrate with a cutting-edge, global dataset of archaeological radiocarbon.

- Expand our current global archaeological radiocarbon datasets, add additional proxies for population and economy size, and publish the expanded dataset.

- Publish papers that use the long-term perspective offered by the integration of formal models and paleodata to evaluate basic concepts from the sustainability literature.

- Collaborate with the LandCover6k working group by developing population growth rates for different regions of the world that will provide baselines for anthropogenic land-use models.

- Build community outreach through our museum partners and exhibits based on the results of PEOPLE 3000 research.

PEOPLE 3000 is an exciting and open network committed to pushing the boundaries of research in human population ecology to provide a firmer foundation for understanding the concept of sustainability. Join our mailing list to receive updates! listserv.unibe.ch/mailman/ listinfo/people3000.pages

\section{AFFILIATIONS}

'Department of Sociology, Social Work, and Anthropology, Utah State University, Logan, USA

${ }^{2}$ The Ecology Center, Logan, USA

Department of Ecology, Pontifical Catholic University of Chile, Santiago, Chile

\section{CONTACT}

Jacob Freeman: jacob.freeman@usu.edu

REFERENCES

Carpenter SR et al. (2015) Proc Natl Acad Sci 112: $14384-14389$

Freeman J et al. (2018) Proc Natl Acad Sci 115: 9962-9967

Lipper L et al. (2014) Nat Clim Change 4: 1068-1072

Robinson E et al. (2019) Adv Archaeol Pract 7: 395-408

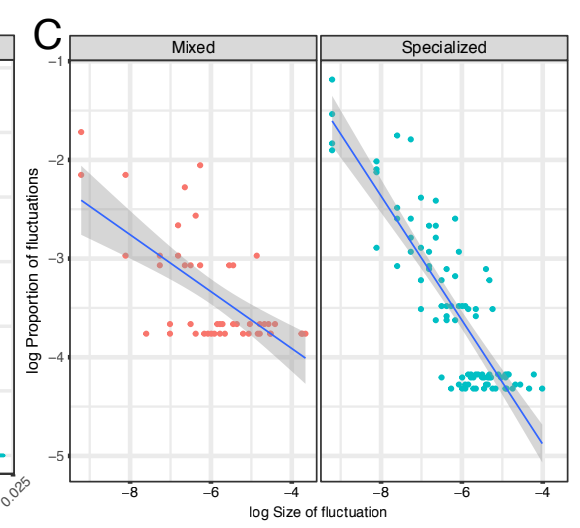

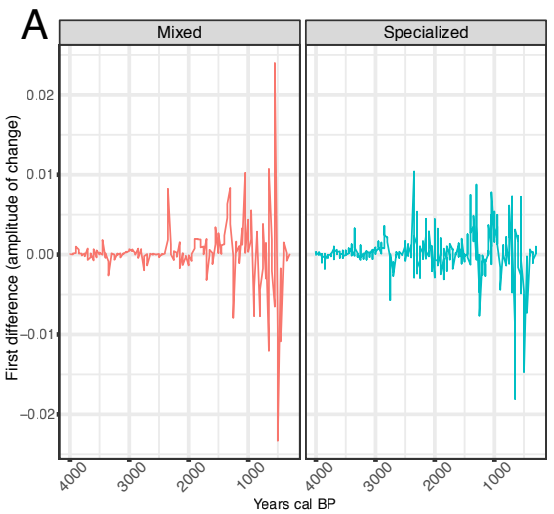

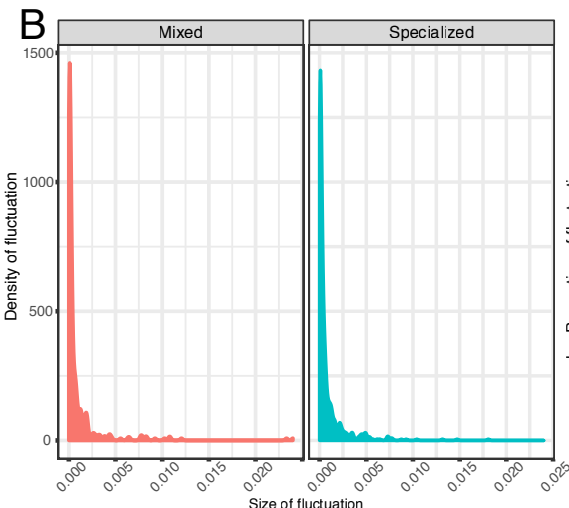

Figure 1: (A) The first difference of summed probability distributions of radiocarbon from mixed forager-farmer and specialized farming societies in North and South America over the last 4000 years cal BP. (B) Density plots of the size of first difference (amplitude of change) and the density of such changes among mixed forager-farmer and specialized farming systems. Note, most changes are small, but a few changes are large. (C) Power functions fit by regressing the log of the size of fluctuation on the log of the proportion (density) of fluctuations. Mixed forager-farmers have a shallower slope indicating more sensitivity to disturbance (more moderate-sized amplitudes of change). Specialized systems have a steeper slope indicating less sensitivity to disturbance. 